\title{
Determination of Copper after Preconcentration as Its 1-Nitroso-2-naphthol Complex onto Activated Carbon
}

\author{
Seung-Hyoun Lee and Hee-Seon Choi ${ }^{*}$ \\ Department of Chemistry: The Lnwersity of Sum on, P.O. Box 77, Sun on 445-743, Korea \\ Received JuIv 25, 2003
}

Key Words : Copper. 1-Nitroso-2-naphthol. Activated carbon. Preconcentration

Copper is a gastrointestinal tract irritant but is generally not harmiful to humans at low $\mu \mathrm{gnL}^{-1}$ concentration. In surface water. however, copper can be toxic to aquatic plants and some fish at concentrations less than $1.0 \mu \mathrm{gni} \mathrm{L}^{-1}$. Thus. copper tends to be much more of an environmental hazard than a human hazard. Most envirommental. biological and alloy samples generally have a trace amount of copper at level of $n \mathrm{gnL}^{-1}$.

In the determination of trace amount of copper. various methods, including ICP-MS. ${ }^{2}$ ion cluromatography. ${ }^{3}$ anodic stripping analysis, ${ }^{4}$ and electrothernal atonic absorption spectrometry have been used. Many of these methods either are time-consuning or require complicated and expensive instruments. ${ }^{6}$ Therefore. other methods that can determine the low concentrations of copper rapidly and conveniently in real samples were required.

Flame atomic absorption spectrometry is a simple and well available technique for the deterninations of many metals in the real samples. Hovever. its main problen is the low sensitivity for trace metals at $\operatorname{ngnL}^{-1}$ level. This linitation can be overcome by the use of a preconcentation procedure

To determine trace metals in real samples, a separation and preconcentration technique is frequently required, because of the trace amount of analyte ions and the presence of interference. ${ }^{7,8}$ For the preconcentration and separation of copper(II) ion. various solid adsorbents such as Amberlite XAD-16 resin, ${ }^{9}$ silica gel. ${ }^{10}$ and benzophenone ${ }^{11}$ have been used. These adsorbents have good preconcentration yields and high recovery yields for some copper(II) complexes. However. these most techniques are troublesome and timeconsuming because of slow sorption and desorption process

Solid phase extraction procedures based on sorption of metal complexes on activated carbon have also applied. ${ }^{13-1+4}$ Activated carbon has been widely used for many purposes both in laboratory and industrial settings. due to its ability to adsorb organic compounds and organic metal complexes. ${ }^{\text {1s }}$ Eurichment of trace metals using activated carbon has been favorably performed with very high concentration factors in different matrices. ${ }^{15}$

Because activated carbon is a type of hydrophobic adsorbent which adsorbs nonpolar or little polar substances in aqueous solution, metal ions to be preconcentrated need to be transformed corresponding metal chelates ${ }^{16-18}$ or metal hydroxides ${ }^{13}$ which could be adsorbed on activated carbon.
Metal chelates could provide higher selectivity and high enriclument factors for such a preconcentration and separation.

The mechanism involved in the adsorption of ions as trace compounds by activated carbon is not completely knowin. It was assumed that the sorption is quantitative when the chelate contains systems of $\pi$-electrons in the molecule and when the centers for binding on carbon and those for the metal ions are spatially separated so that their orbitals do not have a substantial influence. ${ }^{\text {ij }}$

In the present work. a column separation-preconcentration method has been established for the flame atomic absorption spectrometric determination of trace amount of copper separated on activated carbon as 1-nitroso-2-naphthol complex. The proposed technique was applied for the determination of copper in stream water, ground water and diluted brass solution.

\section{Experimental Section}

Reagents and Solutions. All chemicals used in this experiment such as $\mathrm{Cu}\left(\mathrm{NO}_{3}\right)_{2} \cdot 2.5 \mathrm{H}_{2} \mathrm{O}$ (Aldrich $\mathrm{Co}$., USA) were of analytical grade and guaranteed grade reagents. Copper standard solution was made from $1000 \mu \mathrm{gmL}^{-3}$ stock solution. 1-Nitroso-2-naphthol(Merck Co., Germany) stock solution was dissolved in ethanol (Aldrich Co., USA) to be $1000 \mu \mathrm{gmL}^{-1}$. The activated carbon powder used as adsorbent was a granular activated carbon (20-40 mesh) supplied by Aldrich Co. (USA). About a $5 \mathrm{~g}$ amount of activated carbon was stirred with $500 \mathrm{~mL}$ of $3.0 \mathrm{M} \mathrm{HCl}$ for 1 hour, and allowed to stand for $24 \mathrm{~h}$. After filtration, activated carbon was washed with deionized water until it became neutral. and was then dried at $110^{\circ} \mathrm{C}$ for $24 \mathrm{~h}$ in an oven. The deionized water prepared by a Bamstead catridge deionization system (Bamstead, Co. USA) was used throughout all experimental procedures.

Apparatus. GBC model 903 flame atomic absorption spectrophotometer was used in following conditions: $10 \mathrm{~cm}$ l-slot bumer, copper hollow cathode lamp of Photron Dty. Ltd., wavelength: $324.7 \mathrm{~mm}$. air-acetylene flame, bumer height: $15 \mathrm{~mm}$. lamp current: $3.0 \mathrm{~mA}$. Copper in real samples was determined directly with a HP 4500 ICP-MS spectrometer. A Bantex model $300 \mathrm{~A}$ digital $\mathrm{pH}$ meter with a combined glass and calomel electrode was used to adjust the $\mathrm{pHs}$ of all solutions. The glass columm ( $10 \mathrm{~cm}$ long $\times 10 \mathrm{~nm}$ i.d.) was sealed on one end with fritted glass filter $(1-G-1)$ and was 
packed with $0.1 \mathrm{~g}$ of activated carbon.

General Procedures. A $200 \mathrm{~mL}$ copper(II) sample solution was taken into a $250 \mathrm{~mL}$ Erlenmeyer flask. and $1.0 \mathrm{~mL}$ of $1000 \mu \mathrm{gmL}^{-1}$ 1-nitroso-2-naphthol was added. The $\mathrm{pH}$ was adjusted to 10.0 using $0.1 \mathrm{M} \mathrm{NaOH}$. After this solution was stirred for 30 minutes, it was passed through the activated carbon column at a flow rate of $3.5 \mathrm{~mL} / \mathrm{min}$. using aspirator. The desorption of $\mathrm{Cu}(\mathrm{II})$-1-nitroso-2-1naphthol was carried out by treating the activated carbon with $10 \mathrm{~mL}$ portion of $\mathrm{I}$ $\mathrm{M} \mathrm{HNO} 3$ in acetone. The absorbance of copper was measured on the basis of $\mathrm{Cu}$-free blank solution at $324.7 \mathrm{~nm}$ with flame atonic absorption spectrophotoneter. A calibration curve was prepared in the range of $0.005-0.4 \mu \mathrm{gnL}^{-1}$ of copper(II).

A brass sample was prepared as follows. To remove the impurities on the surface of the brass sample. it was washed with acetone and deionized water. A $0.1000 \mathrm{~g}$ brass sample was weighed and transferred to a $250 \mathrm{~mL}$ Erlenmeyer flask.

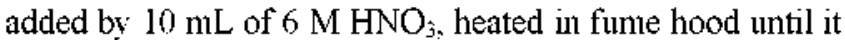
dissolved completely. and cooled down to the room temperature. This brass solution was transferred to $1000 \mathrm{~mL}$ volumetric flask and diluted by filling to the mark. A $1.0 \mathrm{~mL}$ aliquot of the solution was diluted further to a $1000 \mathrm{~mL}$ in a volumetric flask with deionized water and used as a real sample.

A $200 \mathrm{~mL}$ aliquot of stream water or ground water sample was taken after the suspended matters or particles were filtered out with glass filter (1-G-4).

\section{Results and Discussion}

Optimum Conditions. The $\mathrm{pH}$ level is an inportant factor according to which $\mathrm{Cu}(\mathrm{II})$ combine with 1-nitroso-2naphthol to be a stable complex. The $\mathrm{pH}$ of the $200 \mathrm{~mL}$ solution containing $0.15 \mu \mathrm{gmL}^{-1}$ copper(II) and $5 \mu \mathrm{gmL}^{-1} \mathrm{l}$ nitroso-2-naphthol was carefully adjusted from 3.0 to 11.0 with $0.1 \mathrm{M} \mathrm{HNO}_{3}$ or $0.1 \mathrm{M} \mathrm{NaOH}$. The effect of $\mathrm{pH}$ on the separation of $\mathrm{Cu}(\mathrm{II})$-1-nitroso-2-naphthol complex was investigated. The maximum absorbance obtained in the range of $\mathrm{pH} 9.0-10.5$. At acidic $\mathrm{pH}$. it seems that the $\mathrm{Cu}$ (II)1-nitroso-2-naphthol complex was not formed quantitatively on account of protonationing of the chelating agent. At higher $\mathrm{pH}$. it is likely that $\mathrm{Cu}(\mathrm{II})$-1-nitroso-2-naphthol complex was not formed quantitatively because it competed with copper hydroxide precipitation. Hence. $\mathrm{pH} 10.0$ was chosen in this experiment.

To separate metal complex quantitatively. more chelating agent must be added to the sample solution than its stoichiometric ratio. The extraction efficiency in $0.15 \mu \mathrm{gnL}^{-1}$ copper(II) solution was investigated by adjusting concentrations of $1-$ nitroso-2-naphthol from $1 \mu \mathrm{gmL}^{-1}$ to $30 \mu \mathrm{gmL}^{-1}$. The absorbance was practically constant when the concentration of 1 nitroso-2-naphthol was above $3 \mu \mathrm{gmL}^{-1}$. In this experiment. the concentration of 1-nitroso-2-naphthol was used to be 5 $\mu \mathrm{gmL}^{-1}$

The adsorption efficiency of Cu(II)-1-nitroso-2-naphthol complex onto activated carbon was investigated by varying the amount of activated carbon as the adsorbent from 0.03 to $0.30 \mathrm{~g}$. The complex was quantitatively separated at more than $0.08 \mathrm{~g}$ activated carbon. Above $0.20 \mathrm{~g}$, however, it was difficult to use because the elution rate of sample solution was so slow. Thus. $0.10 \mathrm{~g}$ of activated carbon was used as the suitable amount

The effect of flow rate on the adsorption of $\mathrm{Cu}(\mathrm{II})$-1nitroso-2-naphthol was studied. This complex was quantitatively collected at the flow rate in the range of $1 \mathrm{~mL}$ $5 \mathrm{~mL} / \mathrm{min}$. All subsequent experiments were performed at $3.5 \mathrm{~mL} / \mathrm{min}$. flow rate

The desorption of the retained $\mathrm{Cu}(\mathrm{II})-1$-nitroso-2-naphthol complex from the activated carbon column was investigated using various eluent agents such as $+\mathrm{M} \mathrm{HNO}_{3}$. ethyl alcohol, I M NaOH, 0.1 $\mathrm{M}$ acetic acid and $1 \mathrm{M} \mathrm{HNO}_{3}$ in acetone. Quantitative recoveries $(>95 \%$ ) was obtained by 1 $\mathrm{M} \mathrm{HNO}_{3}$ in acetone. The selected volume of eluent was 10 $\mathrm{mL}$ and the recommended desorption rate was $1.0 \mathrm{~mL} / \mathrm{min}$.

Interfering Effects. The possible interfering effects of concomitant ions on the determination of copper(II) were investigated under optimum conditions given above. Various ions were used for investigation of their interference effects on $0.15 \mu \mathrm{gmL}^{-1}$ copper solution, because it was assumed that they prevent the $\mathrm{Cu}(\mathrm{II})$-1-nitroso-2-naphthol complex from forming. The results of interference studies are summarized in Table 1. Co(II) and Ni(II) interfered with more seriously than any other ions. However the interference by these ions could be overcome sufficiently by adjusting the concentration of l-nitroso-2-naphthol to $20 \mu \mathrm{gmL}^{-1}$.

Applications to Real Samples. A calibration curve was constructed at optimum conditions according to general procedure described above. The linear range of $\mathrm{Cu}$ (II) was $0.005 \mu \mathrm{gmL}^{-1}-0.4 \mu \mathrm{gmL}^{-1}$. The correlation coefficient $\left(\mathrm{R}^{2}\right)$ was 0.9983 , showing a good linearity of calibration curve. The detection limit is defined as the sample concentration giving a signal equal to the blank average signal plus three times the standard deviation of blanks. ${ }^{21}$ The detection limit obtained from the signals of twenty-five blank solutions and the slope of calibration curve was $4.4 \mathrm{ngmL}^{-1}$.

$\mathrm{Cu}$ (II) in Suwon stream water, ground water and diluted brass sample were determined by this proposed method and the results are shown in Table 2. The recovery yields in the real samples spiked with 0.10 and $0.20 \mu \mathrm{gmL}^{-1} \mathrm{Cu}$ (II) were determined. and found to be more than $95 \%$. In this determination. the relative standard deviations were less than $5.0 \%$. $\mathrm{Cu}(\mathrm{II})$ in real samples were also determined by ICP-

Table 1. Tolerance limit ${ }^{2}$ for diverse ions in $0.15 \mu \mathrm{g} / \mathrm{mL} \mathrm{Cu(II)}$ solution containing $5 \mu \mathrm{g} / \mathrm{mL}$ 1-nitroso-2-naphthol

\begin{tabular}{cc}
\hline Concentration $(\mu \mathrm{g} / \mathrm{mL})$ & Ions \\
\hline 300 & $\mathrm{Mg}(\mathrm{II}), \mathrm{SCN}^{-}, \mathrm{C}_{2} \mathrm{O}_{4}{ }^{2-}, \mathrm{IO}_{3}{ }^{-}$ \\
100 & $\mathrm{Zn}(\mathrm{II})$, tartarate ion \\
50 & $\mathrm{Al}(\mathrm{III}), \mathrm{Fe}(\mathrm{III}), \mathrm{CN}^{-}$ \\
10 & $\mathrm{Co}(\mathrm{II}), \mathrm{Ni}(\mathrm{II})$ \\
\hline
\end{tabular}

Tolerance limit is the maximum concentration in which there is less than $3^{0} .0$ effect on absorbance. 
Table 2. Analy tical data of Cu(II) in real samples

\begin{tabular}{|c|c|c|c|c|}
\hline \multirow{2}{*}{ Samples } & \multirow{2}{*}{ Spiked $(\mu \mathrm{g} / \mathrm{mL})$} & \multicolumn{2}{|c|}{ Measured $(\mu \mathrm{g} / \mathrm{mL})^{\sigma}$} & \multirow{2}{*}{ Recovery (\%) } \\
\hline & & This techuique & ICP-MS & \\
\hline \multirow[t]{3}{*}{ Stream water (Suwon) } & 0 & $0.039( \pm 0.002)$ & $0.040( \pm 0.002)$ & \\
\hline & 0.10 & $0.135( \pm 0.006)$ & & 96 \\
\hline & 0.20 & $0.242( \pm 0.009)$ & & 102 \\
\hline \multirow[t]{3}{*}{ Ground water } & 0 & $0.038( \pm 0.002)$ & $0.040( \pm 0.002)$ & \\
\hline & 0.10 & $0.139( \pm 0.006)$ & & 101 \\
\hline & 0.20 & $0.234( \pm 0.008)$ & & 98 \\
\hline \multirow[t]{3}{*}{ Diluted brass sample } & 0 & $0.064( \pm 0.003)$ & $0.062( \pm 0.003)$ & \\
\hline & 0.10 & $0.162( \pm 0.008)$ & & 98 \\
\hline & 0.20 & $0.258( \pm 0.009)$ & & 97 \\
\hline
\end{tabular}

"The mean values were obtained from 7 samples in this technique and 5 samples in ICP-MS technique.

MS spectrometry. No difference between results from the proposed method and the ICP-MS method had been established at $95 \%$ confidence level. Therefore. this proposed technique could be applied to the determination of copper(II) in real samples.

\section{References}

1. Sawyer C. N.: McCarty, P. L.: Parkin. G. F. Chemisty for Eniromental Engineering 4th Ed: McGraw-Hill: 1996: $\mathrm{p} 634$.

2. Kato. T.: Nakamura. S.: Mirita. M. Andol. Sci. 1990.6.623.

3. Ohawa. S.: Yamazaki. K.: Ishikawa. T. Bunsekikagaku 1998. 17. 861 .

4. Staden, J. F. Matoetoe, M. C. Anal Chim Acta 2000, H1, 201.

5. Cundeva, K: Stafilov, T. Anal. Lett. 1997, 30,833.

6. Jackson, K. W: Mahnood, T. M. Anat. Chem 1994. 66. 252R

7. Bagheri. H.: Saraii. M.: Naderi. M. Anatos 2000. 125. 1649.

8. Padilha. P.: Rocha. J. C.: Moreira. J. C.: Campos. J.: Federici. C.
Ialamta 1997. +5.317 .

9. Togahoglu. S.: Kartal. S.: Elci. L. Bull. Korean Chent. Soc. 2002. 23.693 .

10. Mahmoud. M. E.: Osman. M. M: Amer. M. E. Anal Chim .Acta $2000 .+15,33$

11. Choi. H. Lee, T. Bull Korean Chem Soc. $2002.23,861$.

12. Soylak. M.: Elci. L.: Dogan. M. Anal. Lett 1999. 33. 513.

13. Giacomelli. M. B. O.: Dasilva. T. B. B.: Curticus. A. T. Talanta 1998. 47.877

14. Yaman. M: Gucer, S. Am. Chim. Rome 1998. 88, 555

15. Cerutti, S.; Silva, M. F.; Gasquez, R. A.: Olsina. R. A.; Martinez. L. D. Spectrochint. Acta B 2003. 58. 43 .

16. Dewi. P. R.: Naidu. G. R. K. Anohwt 1990. 115. 1496.

17. Sattelli. R. E.: Gallego. M.: Valcarcel. M. Tatanta 1994. H1.817.

18. Hall. E. M.: Pelchat. T. C. J Anal At Spectom. 1993. 8. 1059.

19. Koshima. H: Onishi, H. Talanta 1986. 33. 391.

20. Piperaki, E: Berndt, H.: Jackwerth, E. Anal. Chim Acta 1978. 100. 589 .

21. Skoog. D. A.: Holler. F. T.: Nieman1. T. A. Principles of Intmintental Analysis. 5th ed.: Saunders College Publishing: 1998: p 13. 